\title{
Underdiagnosis of Obesity at a Community Health Center
}

Celeste A. Lemay, RN, BSN; Suzanne Cashman, ScD; Judith Savageau, MPH;

Kenneth Fletcher, PhD; Rebecca Kinney, MPH; and Ellen Long-Middleton, RN, PhD

Background: Obesity is at epidemic proportions. This study examined the extent to which obesity is being diagnosed at a community health center residency-training site. Results were examined by provider type. Characteristics of patients with obesity diagnosed by primary care providers were compared with characteristics of patients determined to be obese by body mass index (BMI) calculation exclusively.

Methods: A cross-sectional design was used. Medical records of 465 adult patients were audited. Data collected included diagnosis of obesity, height and weight, demographics, and comorbidity.

Results: Of the 465 patients' charts audited, 83 contained a provider diagnosis of obesity, and 74 additional patients were determined to be obese by BMI calculation exclusively. Significant underdiagnosis occurred among all provider types $(P=.036)$. Patients with a diagnosis of obesity had significantly higher BMI scores $(38.4$ vs $34.4, P=.002)$. Obesity was more likely to be diagnosed in female than in male patients $(P=.001)$. Differences related to age, insurance coverage, and comorbidity were not significant.

Conclusions: Obesity was found to be an underdiagnosed condition among all provider types. As evidenced by significantly higher BMI scores for provider-diagnosed obesity, the data suggest that the obesity diagnosis is made by appearance. The importance of teaching and modeling the use of BMI to diagnose obesity is underscored. (J Am Board Fam Pract 2003;16:14-21.)

Recent data have indicated that obesity is at epidemic proportions in this country and in other countries around the world. ${ }^{1,2}$ In the United States, the prevalence of obesity (body mass index $[\mathrm{BMI}]>$ 30) has increased more than $50 \%$ during the last 20 years, from $14.5 \%$ to $22.5 \%$ of the adult population. ${ }^{3,4}$ Currently, approximately $50 \%$ of the United States population is overweight or obese, with low-income persons, particularly women and people of color, having the highest prevalence rates. ${ }^{5}$

Obesity has been implicated in a variety of longterm, chronic health problems, including diabetes, ${ }^{6}$ hypertension, coronary artery disease, stroke, ${ }^{7}$ hyperlipidemia, and osteoarthritis. ${ }^{4}$ Among women,

Submitted, revised, 14 November 2001.

From the Office of Community Programs (CAL, SC, JS, KF, RK, ELM), University of Massachusetts Medical School, Worcester. Address reprint requests to Celeste A. Lemay, RN, Office of Community Programs/AHEC, University of Massachusetts Medical School, 222 Maple Ave, Chang Building, Shrewsbury, MA 01545.

This publication was made possible through an Inter Service Agency Agreement between the Massachusetts Division of Medical Assistance and the University of Massachusetts Medical School. Its contents are solely the responsibility of the authors and do not necessarily represent the official views of these organizations. this list expands to include depression. ${ }^{8}$ Impaired quality of life and disability, ${ }^{9}$ as well as increased mortality, ${ }^{10-12}$ have also been associated with obesity. Recognition of obesity as a chronic disease requiring long-term management has begun to expand the focus on this condition to include prevention and management, as well as treatment.

The BMI has been recognized worldwide as an effective measure for overweight and obesity by such organizations as the World Health Organization, the National Institutes of Health, and the Centers for Disease Control and Prevention. Calculation of BMI, which is based on a patient's height and weight, provides an objective measure that is reliable, inexpensive, and quick. ${ }^{13}$ Persons are considered to be obese if their BMI is 30 or greater and to be overweight if their BMI is 25 to 29.9..$^{5}$ Because most overweight and obese persons might be seen initially in a primary care setting, this location provides an opportunity for recognition and management of this chronic disease. Given that physicians' advice about health risk interventions has been shown to have positive effects on patient risk status, ${ }^{14}$ it is important that primary care providers not overlook this rapidly increasing health problem. 
Providers might be reluctant to diagnose obesity because of several perceived barriers, including societal stigma, time constraints in the ambulatory care setting, and efficacy of available treatments. ${ }^{15,16}$ In a study of family practice residents' recognition and management of obesity, ${ }^{17}$ however, the lack of a diagnosis in a patient's chart had a negative impact on the counseling patients received. Recent reports in the literature have urged providers to recognize, diagnose, and treat obesity $^{13,18,19}$ as a way of decreasing morbidity and mortality ${ }^{20}$ and reducing attendant psychological, medical, and social costs. ${ }^{21}$

This study examined the extent to which obesity is being diagnosed at a federally funded community health center that serves as a family practice residency site. Results were examined by family practice provider type (eg, physician, nurse practitioner, or resident) to determine who was most likely to diagnose obesity and how the diagnosis was being made (ie, through provider calculation of BMI or observation). The characteristics of patients whose primary care provider diagnosed obesity were compared with characteristics of patients determined by project staff to be obese according to BMI calculations using patients' recorded heights and weights. The importance of providers using a BMI calculation in the delivery of optimal primary health care is underscored.

\section{Methods}

Using a cross-sectional design, the medical records of 465 adult patients who were scheduled to receive care at the center during 1 week in February 1999 were audited. Chart data were examined for a 6-month period preceding the week of the visit (ie, August 1998 to February 1999). Data collected included diagnosis of obesity (recorded by the provider in the progress notes or on the chronic problem list), heights and weights when available,* number of primary care visits in the previous 6 months, demographic characteristics, and the existence of comorbidity (specifically hypertension, diabetes, and depression).

Four registered nurses trained as medical record reviewers audited the patient charts using an exten-

*Patients' heights were noted regardless of when they were obtained; patients' weights were noted only if recorded within the previous 6 months.
Table 1. Demographic Characteristics of Study Sample ( $n=465)$ and Community Health Center (CHC)

Patient Population Overall.

\begin{tabular}{lcc}
\hline & $\begin{array}{c}\text { Study } \\
\text { Sample } \\
\text { No. (\%) }\end{array}$ & $\begin{array}{c}\text { Percent of CHC } \\
\text { Patient Population } \\
\text { Overall* }\end{array}$ \\
\hline Characteristic & & \\
Sex & $136(29)$ & 42 \\
$\quad$ Male & $329(71)$ & 58 \\
$\quad$ Female & & \\
Insurance & $259(56)$ & 45 \\
$\quad$ Medicaid & $45(10)$ & 10 \\
$\quad$ Private & & \\
Race & $4(1)$ & 0 \\
$\quad$ American Indian & $28(6)$ & 12 \\
$\quad$ Asian & $45(10)$ & 32 \\
African American & $159(34)$ & \\
$\quad$ White & & 42 \\
Ethnicity & $188(41)$ & \\
$\quad$ Hispanic & & \\
\hline
\end{tabular}

*Data obtained from Federal Government Uniform Data System Report for the reporting period January 1998 to December 1998.

sive abstraction tool designed for a broader study on outcomes of interdisciplinary, collaborative team practice. Interrater reliability analyses conducted for ordinal and continuous variables produced intraclass correlations ranging from 0.86 to 0.99. Kappa statistics for categorical items ranged between 0.88 and 0.94 . Quarterly meetings were conducted with the nurse abstractors to review data collection techniques.

Data analyses were conducted using the Statistical Package for the Social Sciences. ${ }^{22}$ Frequency distributions were used to describe the patient cohort; bivariate statistical tests to compare groups included the chi-square and $t$ tests, depending on the categorical or continuous nature of the variables. To test for interrater reliability and reliability of provider diagnosis of obesity, the kappa statistic was used for categorical variables and interclass correlation for ordinal and continuous data.

\section{Results}

Table 1 displays selected sociodemographic characteristics of the sample population compared with the health center patient population overall, where applicable. Seventy-one percent $(n=329)$ of the study subjects were female, with a mean age of 41.6 years $(\mathrm{SD}=15$ years) and a range of 18 to 87 years (median 41 years). Most study patients (56\%) were insured by Medicaid. The most prevalent chronic 


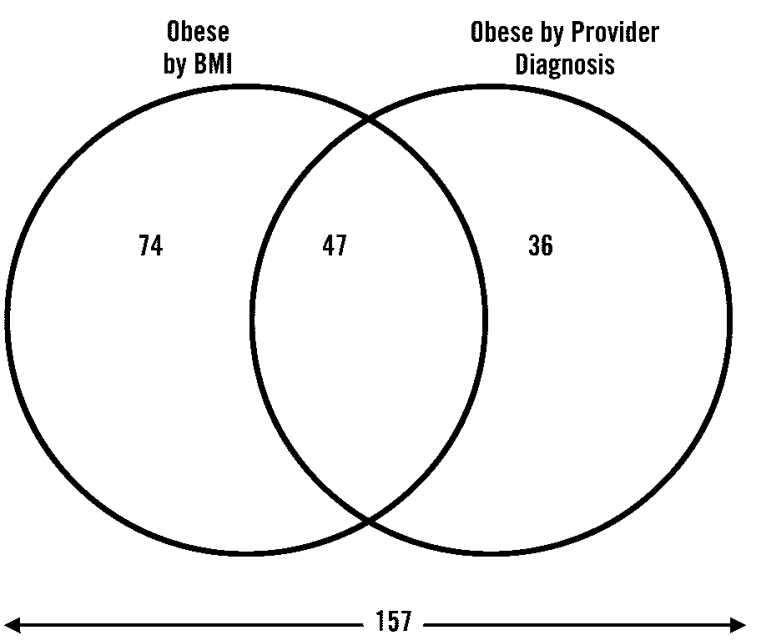

Patients obese by BMI and/or provider diagnosis

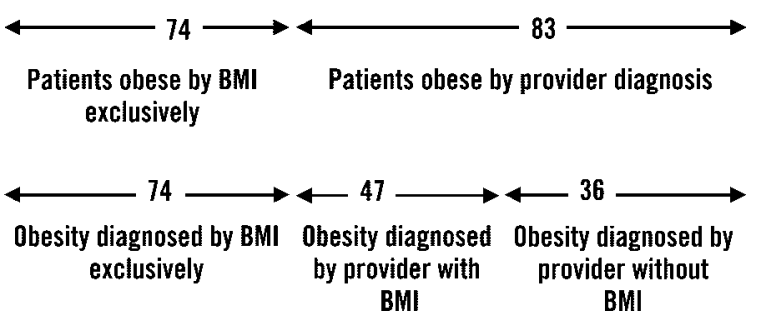

Figure 1. Study sample patients with obesity diagnosed by body mass index (BMI) and by patient's provider $(\mathbf{n}=157)$.

health problems documented in the medical records for this relatively young sample were depression (29\%), hypertension (25\%), asthma (17\%), and diabetes (14\%). In addition, $18 \%$ of patients had obesity diagnosed by their primary care provider.

The diagnosis of obesity was examined by looking at recorded heights and weights to determine the extent to which obesity might have been omit- ted from the chronic problem list in the medical record. Of the 465 adult charts in the sample, 292 charts $(63 \%)$ had the patient's current height and weight, thus permitting research staff to calculate those patients' BMI (Figure 1). Providers diagnosed obesity in 83 of the 465 patients (18\%); only $47(57 \%)$ of these 83 patients had height and weight recorded in their medical records, which allowed for confirmation of the diagnosis. All 47 patients whose providers diagnosed obesity and who also had heights and weights in their medical records were obese according to BMI calculations, with one exception; this patient's BMI was 29.2. An additional 74 (25\% of 292) patients were determined to be obese using BMI calculations, but they had no documented diagnosis of obesity in their medical record. Provider inclusion of a diagnosis of obesity in medical records when a BMI calculation indicated a patient was obese was poor $(\kappa=0.405)$.

The extent to which obesity was diagnosed by provider type (eg, physician, nurse practitioner, or resident) was examined. Significant underdiagnosis occurred among all providers when compared with patients determined to be obese by BMI calculation $\left(\chi^{2}=6.62, d f=2, P=.036\right)$. Physicians recorded a diagnosis for $46 \%$ of their patients whose obesity was determined by BMI, nurse practitioners recorded a diagnosis for $33 \%$, and residents recorded a diagnosis for $17 \%$ (Table 2 ).

Mean BMI scores were compared between patients with provider-diagnosed obesity and patients determined to be obese by BMI calculation alone. The 47 patients with provider-diagnosed obesity who had their height and weight recorded in their chart had a mean BMI of $38.5(\mathrm{SD}=8.2)$. The 74 patients determined to be obese by BMI calculation alone (who did not have a provider-recorded diagnosis) had a mean BMI of $34.4(\mathrm{SD}=4.2)$. Thus,

Table 2. Underdiagnosis of Obesity by Provider Type Among Patients Determined to be Obese by Body Mass Index (BMI) Calculations.

\begin{tabular}{|c|c|c|c|c|}
\hline Diagnosis of Obesity & $\begin{array}{c}\text { Physician } \\
\text { No. (\%) }\end{array}$ & $\begin{array}{c}\text { Nurse } \\
\text { Practitioner } \\
\text { No. }(\%)\end{array}$ & $\begin{array}{l}\text { Resident } \\
\text { No. (\%) }\end{array}$ & $\begin{array}{l}\text { Total(s) } \\
\text { No. (\%) }\end{array}$ \\
\hline Provider diagnosis & $32(46)$ & $7(33)$ & $4(17)$ & $43(37)$ \\
\hline Omission of diagnosis by provider & $38(54)$ & $14(67)$ & $20(83)$ & $72(63)$ \\
\hline Total & $70(61)$ & $21(18)$ & $24(21)$ & $115^{*}$ \\
\hline
\end{tabular}

*Excluded 6 patients who had received primary care from a physician's assistant.

$\chi^{2}=6.62,2 d f, P=.036$.

Linear-by-linear association $=6.53,1 \mathrm{df}, P=.011$.

16 JABFP January-February 2003 Vol. 16 No. 1 
Table 3. Comparison of Patients with Obesity Diagnosed by Primary Care Provider (PCP) and Patients Calculated to be Obese by Body Mass Index (BMI) Exclusively.

\begin{tabular}{|c|c|c|}
\hline $\begin{array}{l}\text { Patient } \\
\text { Characteristics }\end{array}$ & $\begin{array}{l}\text { PCP Diagnosis } \\
\text { of Obesity } \\
(\mathrm{n}=83) \\
\text { No. }(\%)\end{array}$ & $\begin{array}{c}\text { Obese by BMI } \\
\text { Calculation } \\
\text { Exclusively } \\
(\mathrm{n}=74) \text { No. }(\%)\end{array}$ \\
\hline \multicolumn{3}{|l|}{ Sex ${ }^{*}$} \\
\hline Male & $14(17)$ & $31(42)$ \\
\hline Female & $69(83)$ & $43(58)$ \\
\hline \multicolumn{3}{|l|}{ Age, years } \\
\hline $18-25$ & $8(10)$ & $10(14)$ \\
\hline $26-40$ & $27(32)$ & $19(26)$ \\
\hline $41-49$ & $14(17)$ & $17(23)$ \\
\hline $50-64$ & $31(37)$ & $24(37)$ \\
\hline $65+$ & $3(4)$ & $4(5)$ \\
\hline \multicolumn{3}{|l|}{ Insurance } \\
\hline Medicaid & $50(60)$ & $41(55)$ \\
\hline Free care & $5(6)$ & $8(11)$ \\
\hline Private & $6(7)$ & $8(11)$ \\
\hline Medicare & $16(19)$ & $8(11)$ \\
\hline Self-paying & $6(7)$ & $8(11)$ \\
\hline \multicolumn{3}{|l|}{ Racet } \\
\hline American Indian & $1(1)$ & $1(1)$ \\
\hline Asian & 0 & $2(3)$ \\
\hline African American & $10(12)$ & $9(12)$ \\
\hline White & $38(46)$ & $20(27)$ \\
\hline Multiracial, other & $6(7)$ & $7(10)$ \\
\hline Unknown & $28(34)$ & $35(47)$ \\
\hline \multicolumn{3}{|l|}{ Ethnicity $\dagger$} \\
\hline Hispanic & $28(34)$ & $33(45)$ \\
\hline Non-Hispanic & $9(11)$ & $15(20)$ \\
\hline Unknown & $46(55)$ & $26(35)$ \\
\hline \multicolumn{3}{|l|}{ Chronic conditions } \\
\hline Hypertension & $29(35)$ & $24(32)$ \\
\hline Diabetes mellitus & $20(24)$ & $11(15)$ \\
\hline Depression & $28(34)$ & $23(31)$ \\
\hline
\end{tabular}

${ }^{*} \chi^{2}=11.98,1 d f, P=.001$

†Did not test for significance because of missing data.

patients whose obesity was diagnosed by their provider were significantly more obese than patients whose obesity was determined by BMI and for whom the provider did not diagnose obesity $(t=3.19, d f=62, P=.002)$.

The characteristics of patients with providerdiagnosed obesity were compared with those of patients calculated to be obese exclusively by BMI (Table 3). Among these subgroups, women were more likely than men to have obesity diagnosed by their providers. Men, however, were more likely to be obese according to BMI calculations $\left(\chi^{2}=\right.$ $11.98, d f=1, P=$. 001). There were no statistically significant differences in age or insurance coverage between the two groups, nor did they differ significantly with regard to specific comorbid conditions (ie, hypertension, diabetes, and depression).
The number of primary care visits these patients scheduled during the 6-month study period was also examined. Patients with a provider diagnosis of obesity were scheduled to be seen more frequently than were patients with obesity diagnosed by BMI only. Patients with provider-diagnosed obesity had a mean of 3.6 scheduled visits $(\mathrm{SD}=2.8)$ during the 6-month period, whereas patients with BMIonly diagnosed obesity had a mean of 2.8 scheduled visits $(\mathrm{SD}=1.5)$ during the same time $(t=2.28$, $d f=131, P=.024)$.

Additional analyses were conducted to determine the number of patients who were overweight according to BMI calculations. Eighty-three patients were calculated to be overweight (BMI between 25 and 29.9). These patients had a mean BMI of $26.8(\mathrm{SD}=1.4)$.

The patient characteristics associated with obesity (by provider diagnosis or by BMI calculation) and patients who were overweight according to BMI calculation were explored (Table 4). There were no statistically significant differences in sex or insurance coverage between these two groups of patients. There was, however, a nonsignificant tendency for obese patients to be older than their overweight counterparts. The mean age of patients who were obese was 44.2 years $(\mathrm{SD}=13.3$ years); the mean age of patients who were overweight was 40.9 years $(\mathrm{SD}=13.2$ years $)(t=1.87, d f=238$, $P=.063)$. When age was grouped categorically, patients 50 to 64 years of age (compared with all other ages) had a tendency to be obese rather than overweight $\left(\chi^{2}=3.75, d f=1, P=.053\right)$.

Patients who were obese were more likely to have hypertension or diabetes than patients who were overweight $\left(\chi^{2}=4.63, d f=1, P=.031\right.$, and $\chi^{2}=11.62, d f=1, P=.001$, respectively). There was no statistically significant difference between the two groups in the comorbid condition of depression.

\section{Discussion}

In a seminal article on the actual causes of mortality, ${ }^{23}$ researchers concluded nearly a decade ago that obesity was the second leading cause of death in the United States. Since that time, the prevalence of overweight and obesity has increased at epidemic proportions. ${ }^{2,5}$ Despite the rapidly increasing numbers of persons who are obese, however, results of this study indicate that providers in 
Table 4. Comparison of Patients with Obesity Determined by Primary Care Provider (PCP) or Body Mass Index (BMI) Calculation $(\mathrm{n}=157)$ and Patients Overweight Determined by BMI Calculation $(n=83)$.

\begin{tabular}{|c|c|c|}
\hline Characteristics & $\begin{array}{c}\text { Obesity } \\
\text { Determined } \\
\text { by PCP or BMI } \\
\text { No. }(\%)\end{array}$ & $\begin{array}{c}\text { Overweight } \\
\text { Determined } \\
\text { by BMI } \\
\text { No. }(\%)\end{array}$ \\
\hline Sex & & \\
\hline $\begin{array}{l}\text { Male } \\
\text { Female }\end{array}$ & $\begin{array}{r}45(29) \\
112(71)\end{array}$ & $\begin{array}{l}32(39) \\
51(61)\end{array}$ \\
\hline $\begin{array}{l}\text { Age, years } \\
18-25 \\
26-40 \\
41-49 \\
50-64^{*} \\
65+\end{array}$ & $\begin{array}{c}18(12) \\
46(31) \\
31(21) \\
55(37) \\
7(4)\end{array}$ & $\begin{array}{c}13(16) \\
29(35) \\
19(23) \\
19(23) \\
3(3)\end{array}$ \\
\hline $\begin{array}{l}\text { Insurance } \\
\text { Medicaid } \\
\text { Free care } \\
\text { Private } \\
\text { Medicare } \\
\text { Self-paying }\end{array}$ & $\begin{array}{l}91(58) \\
13(8) \\
14(9) \\
24(15) \\
14(9)\end{array}$ & $\begin{array}{c}44(53) \\
11(13) \\
9(11) \\
6(7) \\
11(13)\end{array}$ \\
\hline $\begin{array}{l}\text { Race† } \\
\text { American Indian } \\
\text { Asian } \\
\text { African American } \\
\text { White } \\
\text { Multiracial, other } \\
\text { Unknown }\end{array}$ & $\begin{array}{l}2(1) \\
2(1) \\
19(12) \\
58(37) \\
13(8) \\
63(40)\end{array}$ & $\begin{array}{r}2(2) \\
8(10) \\
9(11) \\
25(30) \\
8(10) \\
31(37)\end{array}$ \\
\hline $\begin{array}{l}\text { Ethnicity } \dagger \\
\text { Hispanic } \\
\text { Non Hispanic } \\
\text { Unknown }\end{array}$ & $\begin{array}{l}61(39) \\
24(15) \\
72(46)\end{array}$ & $\begin{array}{l}34(41) \\
17(20) \\
32(39)\end{array}$ \\
\hline $\begin{array}{l}\text { Chronic conditions } \\
\text { Hypertension } \neq \\
\text { Diabetes mellitus } \$ \\
\text { Depression }\end{array}$ & $\begin{array}{l}53(34) \\
31(20) \\
51(33)\end{array}$ & $\begin{array}{c}17(21) \\
3(4) \\
34(41)\end{array}$ \\
\hline
\end{tabular}

${ }^{*} \chi^{2}=3.75,1 d f, P=.053$.

$+\chi^{2}=4.63,1 d f, P=.031$

$\neq \chi^{2}=11.62,1 d f, P=.001$.

$\S$ Did not test for significance because of missing data.

this primary care setting are not including, when appropriate, a diagnosis of obesity in their patients' medical records. All providers, ie, physicians, nurse practitioners, and residents, significantly underdiagnosed obesity, with residents the least likely to recognize obesity in a patient. Underdiagnosis of obesity is not a new problem. ${ }^{17}$ Nevertheless, the findings reported in this study are timely, because concerns about obesity are receiving increasing amounts of attention from the medical communities $^{15,16,24}$ as well as the public health communities. $^{5,25}$

The reasons given for providers not diagnosing obesity and counseling their obese patients or treating obesity often include provider concerns related to societal stigma and effectiveness of treatment. ${ }^{17}$
The social stigma is real, but so are the threats to health status that obesity poses. Providers, recognizing this negative view of obesity, need to be empathic in their discussions regarding weight management.

Calculating a BMI can be a first step toward using a nonjudgmental, dispassionate clinical indicator to introduce the importance of weight management to a patient. Despite what appears to be conventional wisdom among providers about the intractability of weight management, provider attention to the problem of obesity has been shown to have a positive effect on patients' weight loss. ${ }^{26}$ In a study conducted at a large family medicine training program and practice, investigators concluded that having a diagnosis of obesity recorded in the medical record problem list increased the likelihood that clinical management actions would be taken. ${ }^{17}$

Providers' views of the questionable usefulness of including weight management discussions in the clinical encounter parallel their view decades earlier of the usefulness of addressing tobacco cessation. $^{27-29}$ Before the development of an effective treatment of tobacco addiction (nicotine replacement therapy), the literature was divided on the usefulness of incorporating this element into the primary care visit. Asking patients about smoking habits and counseling them to reduce or quit was not the accepted practice. It appears that we might be at a similar stage of development regarding obesity and whether to address it during a visit. Similar to tobacco use issues, time constraints in the primary care setting, the lack of availability of an effective treatment, and the societal stigma associated with obesity appeared to contribute to providers overlooking this major health concern. These barriers must be overcome to slow and ultimately turn back the epidemic.

The National Institutes of Health clinical guidelines on obesity ${ }^{13}$ recommend that health care professionals discuss weight control with their obese patients; additionally, a recent professional panel recommended that treatment for obesity assume a two-step process of assessment and management. ${ }^{15}$ Management can include prevention of further weight gain ${ }^{16}$ or modest weight loss (5\% to $\left.15 \%\right)$, which has been shown to improve health outcomes, including hypertension, hypercholesterolemia, and diabetes. ${ }^{20}$ According to the results of this study, 
the initial step of assessment does not appear to be occurring with sufficient frequency.

The concern about the prevalence of overweight and obesity is reflected in its having been selected as one of the top 10 leading health indicators in Healthy People 2010. Additionally, medical student activists have chosen obesity as one of two themes for the year. ${ }^{30}$ In a recent American Medical Student Association Community and Public Health Action Committee ${ }^{31}$ list-serve discussion (24 August 2001), medical students pointed out that they, along with their student and resident colleagues, need to learn how to talk to patients about issues related to maintaining a proper weight. They asked that residency training "address physicians' negative attitudes toward treatment as well as their poor knowledge" ${ }^{31}$ of this condition.

Through this list-serve discussion, one family physician who was on the faculty of a teaching program in the Midwest advised residents "to calculate patients' BMI; to include BMI in the vital signs of their oral presentations and written histories and physicals; to discuss obesity as a contributing factor to other conditions in their oral presentations and write-ups; and to counter physicians' frustration and feelings of hopelessness with data on treatments that result in modest, sustained weight loss." ${ }^{31}$ Residents are far more likely to follow through on this recommendation if their faculty mentors are modeling this type of comprehensive approach. According to the results of our study, this type of modeling does not appear to occur with sufficient frequency.

Patients in the current study who had obesity diagnosed by their primary care provider had significantly higher mean BMI scores, suggesting that the diagnosis of obesity was made by appearance, a clinical measure that is less sensitive than BMI. Calculation of BMI scores to assist in the diagnosis of obesity was not evident in patient medical records. Indeed, only 1 of the 465 charts reviewed included a specific BMI. Study investigators noted that $173(37 \%)$ of the 465 patient medical records did not have both height and weight recorded. Consequently, a BMI calculation could not be made for these patients. It is crucial to underscore the importance of obtaining these standard baseline measures in the primary care setting. Current clinical guidelines ${ }^{13}$ recommend calculating a BMI every other year, which can be done only if accurate heights and weights are obtained.
Patients included in this study appear to reflect characteristics of the health center population overall. Although the proportion of female patients captured by this chart audit is higher than the total proportion of the female population of the health center, this discrepancy can be attributed to the study method of selecting patients through visits; female patients tend to make more visits to health care providers than do their male counterparts. ${ }^{32}$

Why the providers were more likely to diagnose obesity in female than male patients is not clear. Perhaps it could be attributed to sex bias and the stigma of obesity, more frequent visits by female patients, self-description by female patients dissatisfied with their bodies, or other factors. Further research to determine the influence of sex of the patient on the diagnosis of obesity is needed.

The existence of comorbidity, specifically hypertension, diabetes, and depression, did not appear to influence the diagnosis of obesity. Patients with provider-diagnosed obesity and those with exclusively BMI-calculated obesity had similar rates of these comorbid conditions, indicating that chronic illnesses linked to obesity did not increase the likelihood of a diagnosis of obesity in the medical record. There was no measure of severity for these comorbid conditions, however. Future research that includes a variety of clinical measures to permit case-mix adjustment would allow researchers to include severity of these comorbid conditions in their analyses.

Patients with provider-diagnosed obesity were scheduled to be seen more frequently by their provider during the 6-month study than patients determined to be obese by BMI calculation. Patients with provider-diagnosed obesity, however, did not experience significantly higher comorbidity. It is unclear whether severity of comorbidity or comorbid factors not included in this study, such as arthritis and chronic pain, are influencing the tendency for patients with provider-diagnosed obesity to be scheduled for more frequent visits. Furthermore, the direction of the association is unclear; that is, whether the obesity diagnosis was the catalyst for more frequent visits or whether more frequent visits result in the provider taking the time to include obesity on the problem list. Nevertheless, this finding is consistent with a recent assessment of physicians' likelihood of counseling patients about exercise; researchers concluded that 
patients with more frequent physician visits were more likely to be counseled. ${ }^{33}$

Patients determined to be overweight by BMI calculation were less likely to have hypertension or diabetes than were patients determined to be obese either by their provider or through BMI calculation alone. These findings are supported in the literature. Obesity, not overweight, is linked to these comorbid conditions. ${ }^{6,7}$ These findings suggest the importance of calculating BMI and determining not only which patients are obese, but also which patients are overweight. Early recognition of a patient's risk of becoming obese might provide opportunities for primary prevention, thus preventing several possible comorbidities.

This study had several limitations. The reliance on medical records for data contributes to the possibility of information bias being introduced by the chart abstraction process. Additionally, because 173 (37\%) of the 465 adult charts audited lacked the patient's current height and weight, our ability to compute BMIs on the total sample and to study more extensively the possible relations between this outcome and sociodemographic and clinical data was limited.

A study conducted at only one site potentially limits the ability to generalize findings to other settings. This type of assessment needs to be performed at additional sites before conclusions can be offered about providers' propensity in general to underdiagnose obesity. Nevertheless, the conclusions drawn are consistent with the literature about providers' likelihood of engaging in behavioral counseling. Additionally, although the number of charts reviewed was sufficient to determine the significance of the findings, empirically fewer patients than desirable were seen by residents to gauge their approach to the diagnosis of this condition.

\section{Conclusions}

In this cohort of patients, obesity was found to be an underdiagnosed condition. All provider types, (physicians, nurse practitioners, and residents, particularly) underdiagnosed obesity. The existence of comorbidity, especially hypertension, diabetes, and depression, was not associated with a diagnosis of obesity in this sample. As evidenced by significantly higher BMI scores in provider-diagnosed obesity, the data suggest that the obesity diagnosis is made by appearance, a less sensitive measure than BMI. Using BMI calculation should aid in the diagnosis of obesity and overweight. Calculating and recording $\mathrm{BMI}$ in medical records during the patient visit can provide opportunities for dialogue, education, and goal setting, thus potentially improving practice and outcomes. Recognition of obesity must occur before a treatment plan can be developed. Barriers to diagnosing obesity have been described. It is time to explore how these impediments can be overcome. The influence of the severity of comorbid disease on the diagnosis of obesity, as well as comorbidities not included in this study, also warrants further examination.

Obesity is a complex chronic health problem that affects a person's physical, psychological, and social well-being. Attention needs to be focused on this potentially reversible health problem. Primary care providers are in the position to recognize the importance of making this diagnosis and include obesity on chronic problem lists as a prompt to discuss dietary and weight-related issues during scheduled visits. Residency faculty are also the role models from whom future physicians and providers are learning the practice high-quality care. By teaching BMI calculation and the importance of diagnosing obesity, primary care providers will increase the future recognition of obesity in the primary care setting and emphasize to residents and medical students the importance of addressing this major public health issue.

The authors wish to acknowledge the contributions of the medical record abstractors Lael Eaton, RN, Christine CuneoLareau, RN, Maria Laverty, RN, and Joan Thorne, RN; and of Annette Hanson, MD, MBA, Director, Office of Clinical Affairs, Division of Medical Assistance.

\section{References}

1. Brown DB, International Obesity Task Force. About obesity. Available at http://www.obesite.chaire.ulaval. ca/iotf.htm. Accessed 10 October 2001.

2. Mokdad AH, Serdula MK, Dietz WH, Bowman BA, Marks JS, Koplan JP. The spread of the obesity epidemic in the United States, 1991-1998. JAMA 1999;282:1519-22.

3. Kuczmarski RJ, Flegal KM, Campbell SM, Johnson CL. Increasing prevalence of overweight among US adults. The National health and Nutrition Examination Surveys, 1960-1991. JAMA 1994;272:205-11.

4. Flegal KM, Kuczmarski RJ, Johnson CL. Overweight and obesity in the United States: Prevalence 
and trends, 1960-1994. City, St: Stockton Press, 1998:39-47.

5. Healthy people 2010 (conference edition, vol 1 and 2). Washington, DC: US Department of Health and Human Services, 2000.

6. Mokdad AH, Ford ES, Bowman BA, et al. Diabetes trends in the U.S.: 1990-1998. Diabetes Care 2000; 23:1278-83.

7. Pi-Sunyer FX. Medical hazards of obesity. Ann Intern Med 1993;119:655-60.

8. Carpenter KM, Hasin DS, Allison DB, Faith MS. Relationships between obesity and DSM-IV major depressive disorder, suicide ideation, and suicide attempts: results from a general population study. Am J Public Health 2000;90:251-7.

9. Han TS, Tijhuis MA, Lean ME, Seidell JC. Quality of life in relation to overweight and body fat distribution. Am J Public Health 1998;88:1814-20.

10. Calle EE, Thun MJ, Petrelli JM, Rodriguez C, Heath CW Jr. Body-mass index and mortality in a prospective cohort of U.S. adults. N Engl J Med 1999;341:1097-105.

11. Allison DB, Fontaine KR, Manson JE, Stevens J, VanItallie TB. Annual deaths attributable to obesity in the United States. JAMA 1999;282:1530-8.

12. Pi-Sunyer FX. Health implications of obesity. Am J Clin Nutr 1991;53:1595S-1603S.

13. Clinical guidelines on the identification, evaluation, and treatment of overweight and obesity in adults: The evidence report. National Institutes of Health. Washington, DC: Government Printing Office, 1998. (NIH publication no. 98-4083.)

14. Kreuter MW, Chheda SG, Bull FC. How does physician advice influence patient behavior? Evidence for a priming effect. Arch Fam Med 2000;9:426-33.

15. Lyznicki JM, Young DC, Riggs JA, Davis RM. Obesity: assessment and management in primary care. Am Fam Physician 2001;63:2185-96.

16. Anderson DA, Wadden TA. Treating the obese patient. Suggestions for primary care practice. Arch Fam Med 1999;8:156-67.

17. McArtor RE, Iverson DC, Benken D, Dennis LK. Family practice residents' identification and management of obesity. Int J Obes Metab Disord 1992;16: 335-40.

18. Nawaz H, Katz DL. American College of Preventive Medicine practice policy statement. Weight management counseling of overweight adults. Am J Prev Med 2001;21:73-8.
19. Logue E, Sutton K, Jarjoura D, Smucker W. Obesity management in primary care: assessment of readiness to change among 284 family practice patients. J Am Board Fam Pract 2000;13:164-71.

20. Oster G, Thompson D, Edelsberg J, Bird AP, Colditz GA. Lifetime health and economic benefits of weight loss among obese persons. Am J Public Health 1999;89:1536-41.

21. Allison DB, Zannolli R, Narayan KM. The direct health care costs of obesity in the United States. Am J Public Health 1999;89:1194-9.

22. SPSS, version 10.0. Chicago: SPSS, 2000.

23. McGinnis JM, Foege WH. Actual causes of death in the United States. JAMA 1993;270:2207-12.

24. Stafford RS, Farhat JH, Misra B, Schoenfeld DA. National patterns of physician activities related to obesity management. Arch Fam Med 2000;9:631-8.

25. Visscher TLS, Seidell JC. The public health impact of obesity. Annu Rev Public Health 2001;22:355-75.

26. Levy BT, Williamson PS. Patient perceptions and weight loss of obese adults. J Fam Pract 1988;27: 285-90.

27. Royce JM, Ashford A, Resnicow K, Freeman HP, Caesar AA, Orlandi MA. Physician- and nurseassisted smoking cessation in Harlem. J Natl Med Assoc 1995;87:291-300.

28. Bronson DL, Flynn BS, Solomon LJ, Vacek P, Secker-Walker RH. Smoking cessation counseling during periodic health examinations. Arch Intern Med 1989;149:1653-6.

29. Rose G, Hamilton PJ, Colwell L, Shipley MJ. A randomized controlled trial of anti-smoking advice: 10-year results. J Epidemiol Community Health 1982;36:102-8.

30. Haque M, CPH Action Committee. Community and public health watch. AMSA Newsletter. Reston, Va: American Medical Student Association, 2001.

31. American Medical Student Association Community and Public Health Action Committee. Obesity list serve discussion. Available at http://www.amsa.org. Accessed 24 August 2001.

32. Utilization of ambulatory medical care by women: United States, 1997-1998 (series 13, no. 149). Hyattsville, Md: Department of Health and Human Services, 2001. (DHHS publication no. 2001-1720.)

33. Wee CC, McCarthy EP, Davis RB, Phillips RS. Physician counseling about exercise. JAMA 1999; 282:1583-8. 